\title{
Um breve histórico da escrita Mundurukú
}

\section{A brief history of Mundurukú writing}

\author{
Gessiane Lobato Picanço ${ }^{1 *}$ \\ https://orcid.org/0000-0001-5699-1470
}

DOI: $10.26512 /$ rbla.v12i1.34083

Recebido em setembro/2020 e aceito em outubro/2020

Resumo

Este estudo discute os momentos que marcaram a formação e a evolução da ortografia da língua Mundurukú (Tupí). O percurso histórico mostra que, até recentemente, a função inicial da escrita na comunidade eram os ensinamentos religiosos. Um dos primeiros textos escritos na língua foi um catecismo, produzido no início do século XX, de autoria de Frei Hugo Mense, missionário franciscano. A constituição do alfabeto da língua ocorreu somente na década de 1960, proposto por missionárias do SIL. É nesse momento que a escrita começa a se tornar uma ferramenta de ensino-aprendizagem da língua materna, apesar de sua função primária ainda ter sido o ensino religioso. Pouco tempo depois o alfabeto passou por uma revisão e alguns grafemas foram alterados, buscando-se alcançar uma semelhança maior com os grafemas da Língua Portuguesa. A análise das correspondências grafofonêmicas mostra que a função da escrita foi determinante para a escolha de quais características do Mundurukú falado deveriam ou não ser representados graficamente, e como essas escolhas impactam o ensino da língua na comunidade.

Palavras-chave: Ortografia. Mundurukú. Função da escrita. Educação indígena. História.

\begin{abstract}
This study describes three defining moments on the spelling formation and evolution of the Mundurukú (Tupí) language. The historical path shows that, until recently, the main function of writing in the community was religious education. One of the first texts written in the language was a catechism, produced in early twentieth century, by Frei Hugo Mense, a Franciscan missionary. The constitution of the Mundurukú alphabet only occurred in the 1960s, proposed by SIL missionaries. At this moment, writing turns to mother tongue education, albeit in a secondary way. Shortly afterwards, the alphabet underwent a revision and some graphemes were altered, seeking to achieve a greater
\end{abstract}

1 Linguista, professora do Instituto de Letras e Comunicação da Universidade Federal do Pará (UFPA), vinculada à Faculdade de Letras e ao Programa de Pós-Graduação em Letras. E-mail: gpicanco@ufpa.br. 
similarity with Portuguese letters. The analysis of letter-sound correspondences shows that the function attributed to writing was decisive for the choice of which features of spoken Mundurukú should be represented graphically, and how these choices affect language teaching in local education.

Keywords: Orthography. Mundurukú. Role fo writing. Indigenous education. History.

\section{Introdução}

Desde que a língua Mundurukú² deixou de ser ágrafa, no início do século XX, sua forma escrita já passou por várias modificações. Destas, a ortografia que se oficializou na comunidade foi a instituída por missionários do Summer Institute of Linguistics (Sociedade Internacional de Linguística - SIL), uma organização evangélica norte-americana, cujos missionários eram linguistas treinados que analisavam línguas indígenas com o propósito de traduzir textos religiosos e, assim, evangelizar a comunidade (Barros 2004). Ela foi implementada na década de 1960, tendo Marjorie Crofts como a principal missionária a conduzir essa empreitada, após sua chegada em 1961 (Crofts 1976). Neste sentido, à exceção do alfabeto revisado proposto por Montserrat (1996), que será discutido mais adiante, o principal interesse em estabelecer-se uma escrita básica para o Mundurukú sempre foi a tradução de textos religiosos, logo, a escrita foi introduzida, e assim permaneceu até recentemente, como meio de doutrinação religiosa, tanto por missionários católicos quanto evangélicos.

Neste artigo, analisaremos três momentos da história da ortografia do Mundurukú, desde o início do século XX até sua configuração atual. Considerase para este estudo a escrita destinada a algum tipo de instrução para a própria comunidade, ou seja, a escrita com fins educativos. Esse percurso histórico é apresentado e discutido separadamente nas seções seguintes, incluindo-se uma análise dos grafemas utilizados para representar os sons da língua.

\section{O livro de catecismo de Frei Hugo Mense}

A primeira obra escrita em língua Mundurukú, com função claramente instrutiva, parece ter sido um catecismo, intitulado Cabi-ä: Pequeno catecismo no idioma mundurucú (Figura 1), que data de 1924. Ele foi produzido por Frei Hugo Mense, missionário franciscano, que chegou à terra dos Mundurukú, no Pará, em 1911, onde ajudou a fundar a Missão Cururu e onde viveu por quase três décadas, dedicando-se "à catequese de seus filhos, como gostava chamar enternecido os seus queridos índios mundurucus" (in Mense 1947, 111).

2 Mundurukú é uma língua pertencente à família de mesmo nome, tronco Tupí (Rodrigues 1986). Os Mundurukú estão localizados principalmente nos estados do Pará, na região do Alto Tapajós, e do Amazonas, na região do rio Madeira. 
Figura 1. Capa do livro Cabi-ä: Pequeno catecismo no idioma mundurucu (Fr. Hugo Mense 1924)

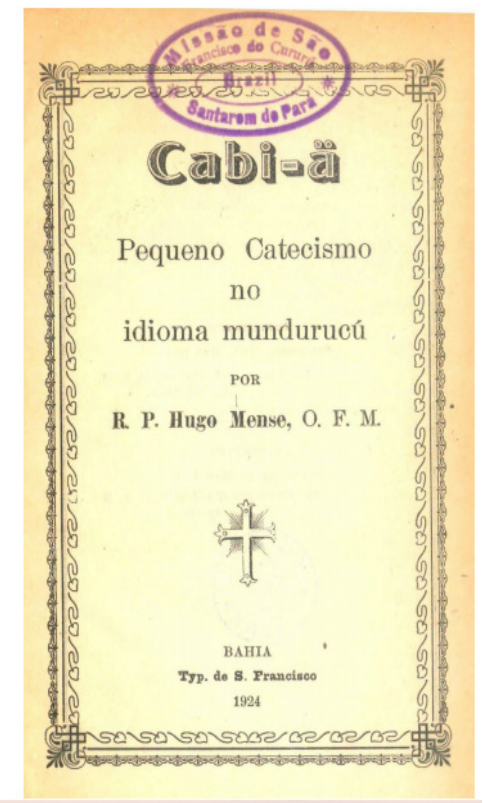

Fonte: Richter e Drummen (2020: 246) - Imagem editada para este trabalho.

Frei Mense deixou uma série de manuscritos sobre a língua Mundurukú, embora não os tenha publicado em sua maioria, segundo Válter Kempf (in Mense 1947). Parte de suas anotações linguísticas aparecem em Língua Mundurucú: vocabulários especiais - vocabulários apalaí, uiabói e maué (Mense 1947), uma publicação póstuma de suas anotações, comentada por R. F. Mansur Guérios, Válter Kempf e Aryon Dall'Igna Rodrigues.

É dessa obra, e das listas de vocábulos que a integram, que recuperamos o que talvez tenha sido o primeiro alfabeto da língua Mundurukú. Nesse estudo, Aryon Rodrigues reproduz, na seção "Vocabulários especiais", uma lista de palavras contendo, basicamente, nomes de animais, plantas, acidentes geográficos, além de nomes de famílias mundurukú. Segundo Aryon Rodrigues (in Mense, 114), a escrita utilizada pelo missionário foi fielmente mantida: "Não alteramos a grafia de fr. Mense em ponto algum." Como não foi possível ter acesso a uma cópia do catecismo para comparar sua forma escrita com a da fonte utilizada para este estudo, assume-se que as escritas sejam análogas.

$\mathrm{Na}$ presente discussão, as correspondências fonético-fonológicas dos grafemas empregados por Frei Mense baseiam-se em trabalhos posteriores da língua (Braun \& Crofts 1965; Crofts 1984; Picanço 2005), visto que não há informações sobre suas pronúncias no estudo publicado. O Quadro 1 mostra os 
fonemas consonantais e seus principais alofones, além de suas correspondências no alfabeto do missionário.

Quadro 1. Sons do Mundurukú e suas correspondentes gráficas no alfabeto de Fr. Mense (1947)

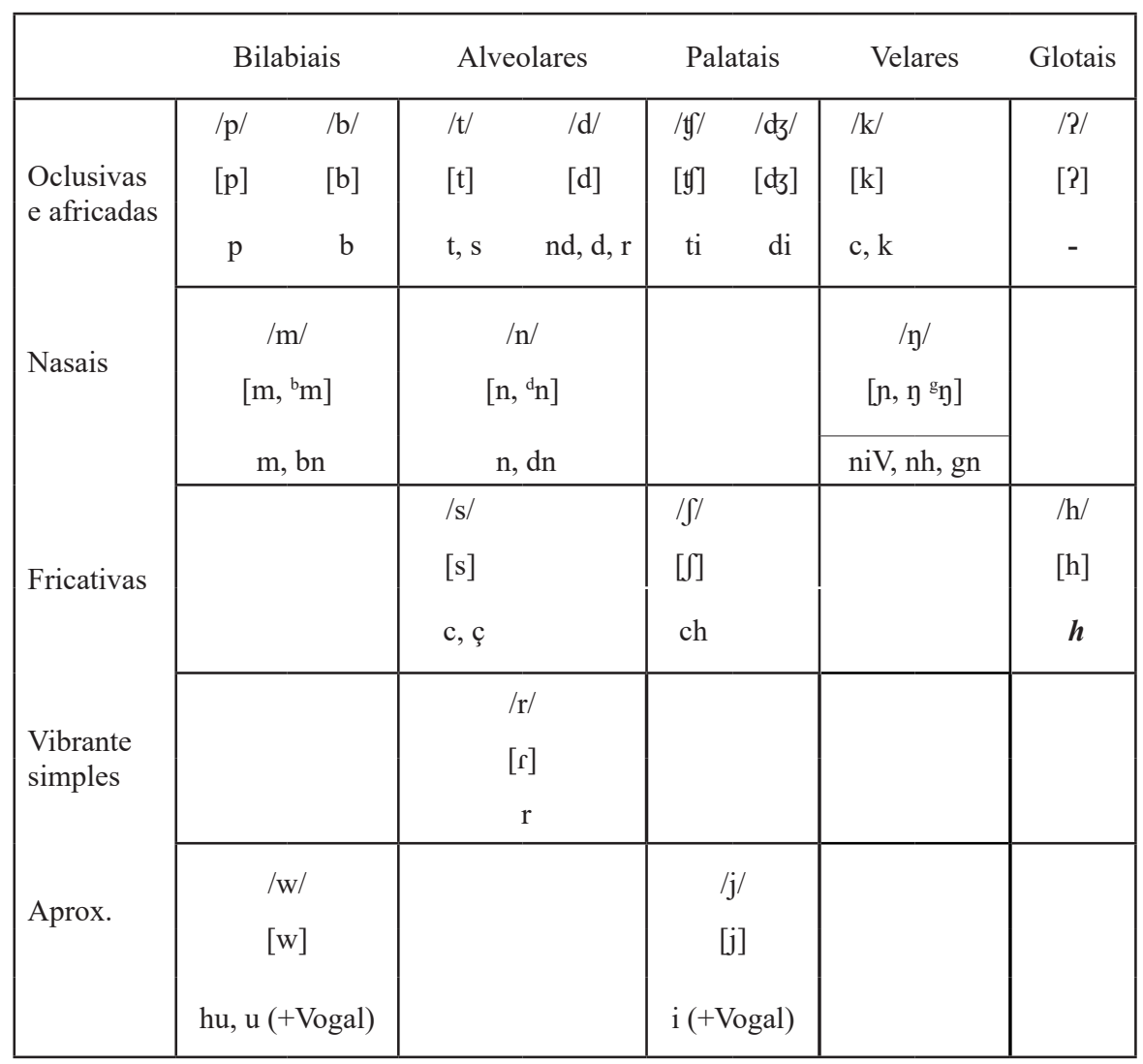

Fonte: Elaborado pela autora.

Pode-se notar que os grafemas são de natureza fonética, provavelmente baseados na percepção que o missionário tinha dos sons dessa língua. Frei Mense demonstrava certa aptidão linguística, se considerarmos a época em que elaborou o alfabeto, ou seja, início do séc. XX. Isso se reflete nas letras e nos diacríticos escolhidos para grafar as palavras, porém respeitando as regras linguísticas da língua indígena.

Para as consoantes, ele faz uso de um conjunto básico de 12 letras, $<$ b, c, $\mathrm{d}, \mathrm{g}, \mathrm{h}, \mathrm{k}, \mathrm{m}, \mathrm{n}, \mathrm{p}, \mathrm{r}, \mathrm{s}, \mathrm{t}>$, para representar os 20 fones consonantais da língua Mundurukú, à exceção da glotal [?], que é consistentemente omitida em sua escrita (p. ex., capé-ip [kape-?ip] 'cafeeiro'). Mais da metade dos grafemas são dígrafos, ou seja, envolve a combinação de duas letras para representar um único som. De modo geral, as transcrições dos sons são relativamente consistentes do ponto de vista fonético-fonológico, podendo-se, inclusive, 
inferir regras na distribuição dos grafemas como referências a regras alofônicas ainda contemporâneas, daí o alfabeto ser uma tentativa de escrever as palavras tal como eram pronunciadas, pelo menos como o padre as percebia.

A seguir listamos algumas de nossas observações sobre os grafemas e sua relação com os sons da língua: ${ }^{3}$

a) As oclusivas [p, t] são representadas por $\langle\mathrm{p}, \mathrm{t}\rangle$, respectivamente, seja em início ou final de sílaba; [t] aparece, algumas vezes, representada por $<\mathrm{s}>$ ou $<\mathrm{t}>$ diante de "i" (p. ex., sikibi /tikibi/ 'pomba' e potíp 'tucunaré'), no que pode ter sido uma tentativa de diferenciar a sequência $\langle\mathrm{ti}\rangle$ de outra, $<\mathrm{ti}+\mathrm{V}>$, correlato de $/ \mathfrak{g} /$ (datié 'gavião real')'. Esse mesmo tipo de combinação é utilizada para grafar /ḑ/ como $<\mathrm{di}+\mathrm{V}>$ (adiurá 'ariramba').

b) As oclusivas sonoras [b, d] são representadas por $<$ b, d $>$, porém $<d>$ possui mais de uma forma grafada: $<\mathrm{d}>$ ocorre quase sempre em início de palavra (datié 'gavião real'), onde, algumas vezes, aparece ainda como $<$ nd $>$ (nduá 'aranha'), talvez por algum efeito de pré-nasalização nesse contexto (cf. Picanço 2005); entre vogais, [d] quase não aparece na lista de Mense e, quando deveria aparecer, é grafada com $\langle\mathrm{r}\rangle$, de modo que /d/ e /r/ confundem-se em sua escrita (pararé/parare/ 'ema' e pörabö'/pədabə/ 'surucucu grande'). ${ }^{4}$

c) A velar [k] tem dois grafemas, $<\mathrm{c}, \mathrm{k}>$, com a seguinte distribuição: $<\mathrm{c}>$ é a mais frequente, aparecendo sempre diante de $<\mathrm{a}, \mathrm{o}, \mathrm{u}>$ ou combinado com $<\mathrm{r}>$, <cr $>$, e em final de sílaba (icupi 'caba'; aric-íp 'caucheiro'); $<\mathrm{k}>$, é usado com menor frequência e diante de outras vogais (kenebidip 'muricizeiro'). $\mathrm{O}$ uso de dois grafemas para um único som parece ser uma tentativa de aproximar a escrita mundurukú à escrita da Língua Portuguesa, cuja letra "c" tem som de $[\mathrm{k}]$ diante das vogais $[\mathrm{a}, \mathrm{o}, \mathrm{u}] \mathrm{e}$ em combinação com outra consoante (casa, cravo, clamor).

d) A alofonia das consoantes nasais $/ \mathrm{m}, \mathrm{n}, \mathrm{y} /$, que exibem alofones os préoralizados $\left[{ }^{\mathrm{b}} \mathrm{m},{ }^{\mathrm{d}} \mathrm{n},{ }^{\mathrm{g}} \mathrm{n}\right]$ em final de sílaba, após vogal oral, parece ter sido também incorporada à escrita de Fr. Mense, ao utilizar as sequências $<$ bn, dn, gn> (aridn-á 'sem trad.'; ip-tiegn-tiegn-íp 'sem trad.'). Do

3 As traduções dos termos foram mantidas conforme aparecem em Mense (1947), mas nem todos os vocábulos incluem tradução; esses casos são indicados por "sem trad.". As formas fonêmicas foram adicionadas aos exemplos, quando necessárias, para fins de comparação. Essas formas apenas mostram a correspondência segmental, não sendo marcados nem o tom nem a laringalização.

4 O dialeto Mundurukú do Amazonas exibe somente [ $\mathrm{r}$ ], tendo já neutralizado o contraste entre /d/ e /s/ em qualquer contexto (Crofts 1967; Picanço 2012a). Na primeira análise da fonologia Mundurukú, Braun e Crofts (1965) também reportaram somente o tepe [r], e não a oclusiva [d], mas que depois foi reanalisada como um fonema distinto, "apesar de [/d/] se achar em distribuição quase complementar com os fonemas /r/ e /n/” (Crofts 1967: 89). 
mesmo modo, $<$ niV $>$, algumas vezes $<$ nh $>$, refere-se ao alofone palatal [n], de /y/, em ataque silábico (aniöpä̈' 'mandubé').

e) A regra de uso dos grafemas para a fricativa alveolar [s] é dada por Rodrigues (in Mense 1947, 115) como $<\mathrm{c}>$ diante de $<\mathrm{e}, \mathrm{i}>$, e $<\mathrm{c}>$ diante de $<$ a, o u, ä, ö $>$ (çapucái 'galinha'), sugerindo outra provável influência do português. A outra fricativa, [J], é representada por $<\mathrm{ch}>$ (achimán 'peixe').

f) Os glides [w, j] são grafados com as vogais $\langle\mathrm{u}, \mathrm{i}>$, respectivamente, como nos ditongos do português. O glide $/ \mathrm{j} /$ aparece somente com $<\mathrm{i}>$ nas formas escritas (hacai-ip 'taperebazeiro'; iuba-ip /joba-Pip/ 'jaboticabeira'); porém, /w/ tem duas formas: $<\mathrm{hu}>+\mathrm{V}$ (huacará / wakara/ 'gaivota') ou somente $<\mathrm{u}>+\mathrm{V}$ (mauö' 'inambú preto'). $<\mathrm{h}>$ também tem a função de marcar $/ \mathrm{h} /$, mas aparece mais no início da palavra (hacai-ip 'taperebazeiro'), contexto onde [h] é usualmente epentético (Picanço 2005).

g) Para as vogais, o alfabeto de Frei Mense é menos transparente, principalmente em relação às vogais assinaladas com um trema (ö e ä) e a marcação da nasalidade. A língua distingue cinco qualidades vocálicas, /i, e, ə, a, o/, além de contrastes de nasalidade, tom e laringalização (Braun \& Crofts 1965; Picanço 2005). Em relação ao tom e a laringalização, sabe-se que estes tornaram-se conhecidos somente após a chegada dos missionários do SIL, em particular, de Sarah Gudschinsky, em 1959, conforme relata Crofts (1976). O acento agudo, ou o apóstrofo, ${ }^{5}$ que Frei Mense (1947) assinala nas vogais, quase sempre na última vogal da palavra, marca o acento de intensidade. Além disso, as formas grafadas não parecem indicar que ele tenha percebido a laringalização. São seis os grafemas utilizados para as vogais: $<\mathrm{i}, \mathrm{e}, \mathrm{a}, \ddot{a}, \mathrm{o}, \ddot{\mathrm{o}}, \mathrm{u}>$. Diferentemente das consoantes, o número de grafemas para as vogais ultrapassa o total de vogais da língua, sem uma distribuição evidente.

h) As vogais sem trema $<$ i, e, a $>$ correspondem a $[i, \varepsilon, a]$, respectivamente. No entanto, $[\varepsilon]$, tem uma segunda representação, $<a ̈>$, como em aniöpä'

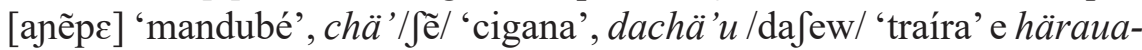
ip /erawa-Pip/ 'biribá', percebendo-se claramente a influência do alemão, a língua materna de Frei Mense. $\mathrm{O}$ uso de $<\mathrm{e}>\mathrm{e}<\ddot{\mathrm{a}}>$ para representar a mesma vogal parece ter sido uma escolha aleatória. Por exemplo, em äréc e änéc, formas gráficas para /erẽk/ 'anum', <e> representa /e, ẽ/,

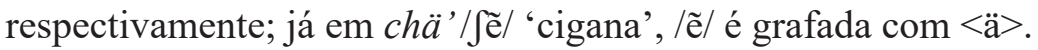

i) As vogais $<_{0}, \mathrm{u}>$ correspondem a uma única vogal /o/ [o], mas que, foneticamente, alterna com $[\mathrm{u}] ;<\mathrm{u}>$ também é usado para representar o glide $/ \mathrm{w} /$, assim como $<\mathrm{i}>$ representa o glide $/ \mathrm{j} /$, explicados anteriormente.

$5 \mathrm{O}$ apóstrofo é usado quando a vogal carrega o trema (mauö' 'inambú preto'). 
j) A outra vogal que recebe o trema é $<\ddot{0}>$. Das palavras reconhecidas na lista, $<\ddot{0}>$ corresponde à vogal central /ə/, como nos exemplos: çörá / səra/ 'gavião panema', pöi-bö'/pəjbə/ 'cobra', daröc-pac-pác /darəkpak-pak/ 'arco pintado de vermelho'.

k) A nasalidade da vogal, embora um traço fonológico importante na língua, ou não é marcada (huena-rip-á /wenว̃-dip-?a/ 'morro do castanhal'), ou, quando marcada, parece ser pela sequência $\langle\mathrm{Vn}\rangle$ : huetún [witõ witũ] 'mutum', achimán [a aimã] 'peixe', confundindo-se às consoantes nasais de final de sílaba.

Apesar de essa ter sido a primeira grafia da língua Mundurukú, sua função principal não era o ensino da língua na comunidade, mas ser um importante instrumento para converter os nativos à religião católica. É o que se constata nos relatos sobre o período referente à atuação da missão fransciscana (Kempf 1944; Covellatti 2009). Baseando-se nos Diários da Missão São Francisco (DMSF), Covellatti (2009) reporta que o ensino nas escolas da Missão voltavase para o ensino do Português e a instrução religiosa, realizada também na língua indígena. Desse modo, a princípio, a escrita parecia servir muito mais ao aprendizado dos missionários, para que pudessem ensinar a religião, do que aos próprios Mundurukú, como descreve Covellatti $(2009,637)$ :

Nas escolas da Missão, por sua vez, o ensino era voltado para o aprendizado do português e da matemática, além de uma educação técnica para as crianças: as irmãs iniciavam as meninas nos serviços domésticos, tais como cozinhar e costurar, e os padres ensinavam aos meninos técnicas de agricultura, carpintaria, mecânica e construção de canoas. Quanto à instrução religiosa, todos aprendiam as principais orações, como o Pai Nosso e a Ave Maria, além das "verdades religiosas" sobre Deus e Jesus Cristo, em português e munduruku.

\section{A chegada dos missionários do SIL}

O segundo momento que marcou a história da escrita da língua Mundurukú ocorreu aproximadamente cinco décadas após a fundação da missão franciscana, com a chegada de outros missionários, em 1959, desta vez do Summer Institute of Linguistics (Sociedade Internacional de Linguística-SIL). Como dito anteriormente, os missionários do SIL eram linguistas treinados que estudavam uma língua, principalmente as indígenas, visando a evangelização da comunidade através da tradução de textos religiosos (Barros 2004). Portanto, o segundo período da escrita mundurukú também teve como objetivo principal o ensino religioso.

Por outro lado, a presença do SIL contribuiu significativamente para o reconhecimento da importância da língua dentro da Linguística, pois deve- 
se a um de seus membros, Sarah Gudschinsky, a descoberta de que a língua exibe contrastes de tom e laringalização, conforme relata Crofts (1976). Outra contribuição deixada por esses missionários foram as várias publicações de materiais linguísticos e didáticos, incluindo gramáticas, dicionários, cartilhas de alfabetização, livros sobre mitos e lendas etc. Por fim, esse foi também o período do desenvolvimento de uma ortografia mais funcional para a língua Mundurukú, isto é, reconhecida e empregada na educação escolar.

Marjorie Crofts foi a principal linguista e missionária do SIL que conduziu o trabalho de elaborar e implementar a escrita mundurukú, a partir de sua chegada em 1961. ${ }^{6}$ A motivação para o trabalho com a língua era, outra vez, religiosa, ou seja, traduzir a Bíblia e canções e textos religiosos. A imagem abaixo mostra uma página do texto bíblico O Evangelho segundo São Marcos (SIL 1967), já traduzido na recém-criada ortografia da língua.

Figura 2. Recorte do texto bíblico O Evangelho segundo São Marcos em Mundurukú

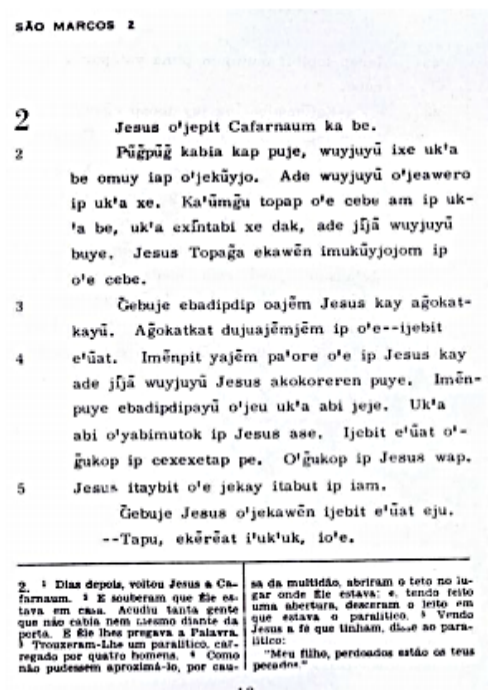

Fonte: Extraído de Góes Neto (2015: 80) - Imagem editada para este trabalho.

Linguistas de formação, Braun e Crofts (1965) preocuparam-se em analisar previamente a fonologia do Mundurukú e elaborar um esboço da gramática que, embora seja de 1966, só foi publicado mais tarde (Crofts 1973). Publicações posteriores sugerem que a análise fonológica foi levemente revisada, em especial quanto ao número de fonemas. Braun \& Crofts estabeleceram 16 fonemas consonantais, não incluindo /d/, que depois foi reconhecido como um

6 Crofts (1973) relata que visitou primeiramente um grupo Mundurukú no Amazonas, entre 1961 e 1962, e só depois fixou residência em uma aldeia Mundurukú do Pará, lá permanecendo até o final dos anos 1980. 
fonema (Crofts 1967, 1985). A ortografia instituída já reflete essa revisão do inventário fonêmico e é de natureza fonêmica. Em outras palavras, os grafemas representam os sons que têm valor distintivo, por isso a correspondência grafema-fonema é unívoca, em que um grafema representa um único fonema, e cada fonema é representado por um grafema distinto. Desse modo, o alfabeto é composto por 22 letras, sendo 17 para as consoantes e 5 para as vogais; as vogais nasais correspondentes recebem o til, $<\tilde{\mathrm{a}}, \tilde{\mathrm{e}}, \tilde{\mathrm{i}}, \tilde{\mathrm{o}}, \tilde{\mathrm{u}}>$. A ordem das letras do alfabeto mundurukú é como segue, segundo a proposta de Picanço (2012b).

Quadro 2. Alfabeto Mundurukú

\begin{tabular}{|ccccccccc|}
\hline $\mathbf{A} \mathbf{a}$ & $\mathbf{B} \mathbf{b}$ & $\mathbf{C} \mathbf{c}$ & $\mathbf{D} \mathbf{d}$ & $\mathbf{E} \mathbf{e}$ & $\tilde{\mathbf{G}} \mathbf{g}$ & $\mathbf{H} \mathbf{h}$ & $\mathbf{I} \mathbf{i}$ & $\mathbf{J} \mathbf{j}$ \\
$/ \mathrm{a} /$ & $/ \mathrm{b} /$ & $/ \mathrm{t} /$ & $/ \mathrm{d} /$ & $/ \mathrm{e} /$ & $/ \mathrm{y} /$ & $/ \mathrm{h} /$ & $/ \mathrm{i} /$ & $/ \mathrm{d} /$ \\
$\mathbf{K} \mathbf{k}$ & $\mathbf{M} \mathbf{m}$ & $\mathbf{N} \mathbf{n}$ & $\mathbf{O} \mathbf{0}$ & $\mathbf{P} \mathbf{p}$ & $\mathbf{R} \mathbf{r}$ & $\mathbf{S} \mathbf{s}$ & $\mathbf{T} \mathbf{~ t}$ & $\mathbf{U} \mathbf{u}$ \\
$/ \mathrm{k} /$ & $/ \mathrm{m} /$ & $/ \mathrm{n} /$ & $/ \mathrm{d} /$ & $/ \mathrm{p} /$ & $/ \mathrm{r} /$ & $/ \mathrm{s} /$ & $/ \mathrm{t} /$ & $/ \mathrm{a} /$ \\
$\mathbf{W} \mathbf{w}$ & $\mathbf{X} \mathbf{x}$ & $\mathbf{Y} \mathbf{y}$ &, & & & & & \\
$/ \mathrm{w} /$ & $/ \mathrm{S} /$ & $/ \mathrm{j} /$ & $/ 2 /$ & & & & & \\
\hline
\end{tabular}

Fonte: Adaptado de Picanço (2012b, 40)

Em termos de profundidade ortográfica (Katz \& Frost 1992), a ortografia proposta por Crofts e colegas pode ser definida como superficial, pois as representações gráficas refletem tanto os fonemas quanto as variantes morfofonêmicas de morfemas.

O texto a seguir, extraído de um livro de lendas mundurukú, ilustra bem a transparência, na escrita, de alguns processos morfofonológicos da língua. Um deles é a alternância de vozeamento, que afeta a consoante inicial de uma série de morfemas, incluindo verbos, nomes, posposições etc. (Picanço 2005). Essas consoantes assumem a forma vozeada $(/ b, d, d z /)$ após vogais e glides, e a forma surda $(/ \mathrm{p}, \mathrm{t}, \mathrm{t} /)$ após outras consoantes; os grafemas correspondentes a eles são $<\mathrm{b}, \mathrm{d}, \mathrm{j}>\mathrm{e}<\mathrm{p}, \mathrm{t}, \mathrm{c}>$, respectivamente. Na escrita, os morfemas afetados pela alternância são grafados das duas formas, podendo iniciar por $\langle\mathrm{b}, \mathrm{d}, \mathrm{j}\rangle$ ou por $<\mathrm{p}, \mathrm{t}, \mathrm{j}>$, daí termos jĩjã $/$ cica a 'muito', butet/putet 'nome', e be/pe 'LOCATIVO'. Ainda nessa mesma linha, tem-se soat/soan, em que $<\mathrm{n}>$ final resulta de outro processo de assimilação $(\mathrm{t}+\mathrm{m} \rightarrow \mathrm{n})$, por conta da combinação soat 'todos/tudo' + -m 'ASPECTO'; e, por fim, tem-se taybit/taybitbicat, devido à palatalização do $/ \mathrm{t} /$ final $(\mathrm{t} \rightarrow \mathrm{c})$, proveniente da combinação taybitbit 'ser sabido-RED $+i$-at '3-NOM'.

Soat mug̃ẽg̃ẽm ixe o sunuy. Ade iĩjã wuyjuyũ cucum cekay, soan itaybit puye. Da'i mujurũgrũ̃ goat pe am. Jadaibu i ibutet. Tawejadaibu i ibutet - ixe ag̃oka kukat putet - itaybitbicat putet. Iixĩt putet osunuy Tawebire i. Itaybit cĩcã osunuy. Tog̃ãm itaybit 
osunuy. Soat ceda'im osunuy jekipit puxim ma. Ikipit tak itaybit cĩcã osunuy. Adai'adai be ip dopdom jeda'i'i'in (Cabá \& Sau 1978, 33; grifos e destaques nossos).

Se por um lado, a proposta ortográfica reflete com exatidão as alternâncias morfofonêmicas envolvendo segmentos, por outro, ela deixou de fora dois importantes traços suprassegmentais da língua - o tom e a laringalização. A decisão de não sinalizá-los na escrita básica é compreensível, já que Crofts sempre sustentou um sistema de quatro tons para o Mundurukú: super-alto, alto, baixo e o de laringalização (Braun \& Crofts 1963; Crofts 1973, 1985); marcá-los, até mesmo parcialmente, exigiria um número maior de diacríticos. Crofts (1976) discute essa e outras questões, que foram consideradas na época, para definir se era ou não essencial marcar os tons na escrita. Nesse artigo, a autora demonstra preocupação com as prováveis ambiguidades que a ausência de marcação tonal geraria na tradução de textos religiosos, revelando a função elementar da escrita enquanto instrumento de evangelização na comunidade. Por fim, a decisão foi não sinalizar esses suprassegmentos na ortografia, embora estes não tenham sido completamente omitidos; cartilhas e livros de leitura produzidos para a alfabetização fazem uso da forma básica (sem tons), enquanto a gramática (Crofts 1985) marca os tons por meio de números sobrescritos: $1=$ tom super-alto, $2=$ tom alto, $3=$ tom baixo, $4=$ laringalização (p. ex., $a^{2} \mathrm{ko}^{3} \mathrm{ba}^{4}$ 'banana'). Essa decisão teve uma vantagem. Análises mais recentes do sistema tonal comprovam que a língua possui um sistema de somente dois, e não quatro tons contrastivos, limitando-se a alto e baixo (Picanço 2005). Sendo assim, assinalar os tons desnecessariamente poderia comprometer não só o ensino-aprendizagem da língua escrita, gerando redundâncias, como também a produção de materiais didáticos, pelo uso excessivo de diacríticos. Entretanto, a maior desvantagem da ausência dos tons na escrita refere-se à dificuldade enfrentada por não falantes da língua, como é o caso da comunidade Mundurukú do Amazonas, onde a língua nativa foi substituída pelo Português. Para eles, seria fundamental que a escrita fornecesse as pistas desse traço fonológico tão importante da língua falada.

\section{A revisão ortográfica}

Um encontro para discutir a ortografia ocorreu em maio de 1996, com a participação de professores indígenas e a assessoria da linguista Ruth Fonini Monserrat, que coordenou o curso de Revisão ortográfica da língua Mundurukú, conforme relata Monserrat (1996). Ainda segundo a linguista, cerca de 10 anos antes, outro encontro havido sido promovido, no qual decidiu-se rever algumas letras do alfabeto, porque "havia uma crítica difusa sobre o uso de certas letras, que não seriam muito adequadas para o ensino, em ambiente de fala portuguesa." (Idem, 1) A confusão a que se refere Monserrat é no uso de letras 
como, por exemplo, $<\mathrm{u}>$, que tem som de [u] no Português, mas representa [ə] no Mundurukú; $<\mathrm{c}>$, com som de [k, s] na primeira, e [t] na segunda; ou $<\tilde{\mathrm{g}}>$, que representa tanto o som palatal [n], familiar a falantes de Português como "som de $n h$ ", quanto o velar [ $\left.{ }^{\mathrm{g}} \mathrm{y}, \mathrm{\eta}\right]$, menos perceptível aos que não falam a língua. Sendo assim, a motivação para a revisão da ortografia ocorreu porque era preciso tornar a escrita mundurukú mais inteligível a falantes do português.

As alterações feitas no alfabeto aparecem no manuscrito Vocabulário Mundurukú-Português, de autoria de Monserrat (1996) ${ }^{7}$, uma espécie de vocabulário ortográfico contendo, de um lado, uma lista de palavras escritas já com a grafia revisada e, do lado oposto, as palavras escritas com a grafia anterior, dos missionários do SIL. O Quadro 2 mostra o alfabeto e suas correspondentes fonético-fonológicas, seguindo a ordem das letras proposta por Monserrat (1996). Embora a maioria dos grafemas da proposta anterior tenha sido mantida, o alfabeto incorpora algumas representações fonéticas, em particular, do fonema velar /y/, cujas variantes são escritas como $<$ nh $>$ para [n], $<$ gn $>$ para $\left[{ }^{g} \mathrm{n}\right]$ e $<$ ng $>$ para $[\mathrm{y}] ; \mathrm{e}<\mathrm{u}>$ que representa as variantes [o $\mathrm{u}]$. Monserrat lista somente $<\mathrm{nh}>$ no alfabeto, porém $<\mathrm{gn}$, ng $>$ aparecem nas palavras grafadas no vocabulário, por isso foram incluídas no quadro.

\section{Quadro 3. Alfabeto Mundurukú revisado}

\begin{tabular}{|ccccccccc|}
\hline $\mathbf{a}$ & $\hat{\mathrm{a}}$ & $\mathbf{b}$ & $\mathbf{d}$ & $\mathbf{e}$ & $\mathbf{h}$ & $\mathbf{i}$ & $\mathbf{j}$ & $\mathbf{k}$ \\
$/ \mathrm{a} /$ & $/ \mathrm{a} /$ & $/ \mathrm{b} /$ & $/ \mathrm{d} /$ & $/ \mathrm{e} /$ & $/ \mathrm{h} /$ & $/ \mathrm{i}, \mathrm{j} /$ & $/ \mathrm{d} /$ & $/ \mathrm{k} /$ \\
$\mathbf{m}$ & $\mathbf{n}$ & $\mathbf{n h}, \mathbf{g n}, \mathbf{n g}$ & $\mathbf{p}$ & $\mathbf{r}$ & $\mathbf{s}$ & $\mathbf{t}$ & $\mathbf{t x}$ & $\mathbf{u}$ \\
$/ \mathrm{m} /$ & $/ \mathrm{n} /$ & {$[\mathrm{n}, \mathrm{g}, \mathrm{j}, \mathrm{j}]$} & $/ \mathrm{p} /$ & $/ \mathrm{r} /$ & $/ \mathrm{s} /$ & $/ \mathrm{t} /$ & $/ \mathrm{g} /$ & {$[\mathrm{o} \sim \mathrm{u}]$} \\
$\mathbf{w}$ & $\mathbf{x}$ &, & & & & & & \\
$/ \mathrm{w} /$ & $/ \mathrm{g} /$ & $/ \mathrm{r} /$ & & & & & & \\
\hline
\end{tabular}

Fonte: Elaborado pela autora com base em Monserrat $(1996,2)$

A revisão envolveu basicamente a retirada e substituição de grafemas, para tornar a escrita "mais parecida com o português" (Monserrat 1996, 2). Do alfabeto precedente, foram retiradas as letras $<0>$, que foi substituída por $<\mathrm{u}>$; $<\mathrm{c}>$, substituída por $\langle\mathrm{tx}>$; e $<\mathrm{y}\rangle$, que passou a ser representada somente pela vogal $<\mathrm{i}>$, pois " $y$ poderia ser vantajosamente substituída em todos os ambientes pela letra $i$." (Ibidem) A vogal central / $/ \mathrm{\partial} /$, antes grafada por $<\mathrm{u}>$, passou a $<\hat{\mathrm{a}}>$, e $/ \mathrm{g} /$ passou a $<\mathrm{tx}>$, enquanto $/ \mathrm{d} /$ permaneceu $<\mathrm{j}>$. O Quadro 4 compara os dois alfabetos, com destaque aos grafemas alterados e não alterados.

7 Meus agradecimentos à professora Ruth Monserrat por ter-me cedido uma cópia desse trabalho original. Uma versão do vocabulário Mundurukú-Português foi publicada em Monserrat (2000). 
Quadro 4. Comparação dos alfabetos propostos por SIL e Ruth Monserrat

\begin{tabular}{|c|c|c|}
\hline $\begin{array}{l}\text { CROFTS-SIL } \\
(\operatorname{anos} 60)\end{array}$ & $\begin{array}{c}\text { MONSERRAT } \\
(1996)\end{array}$ & $\begin{array}{l}\text { FONEMAS/SONS } \\
\text { REPRESENTADOS }\end{array}$ \\
\hline $\mathrm{u}$ & $\hat{\mathrm{a}}$ & $/ a /$ \\
\hline o & $\mathrm{u}$ & {$[\mathrm{o} \sim \mathrm{u}]$} \\
\hline $\mathrm{i}, \mathrm{y}$ & $\mathrm{i}$ & $/ \mathrm{i} /, / \mathrm{j} /$ \\
\hline$\tilde{\mathrm{g}}$ & $\mathrm{nh}, \mathrm{gn}, \mathrm{ng}$ & {$\left[n,{ }^{g} \eta, y\right]$} \\
\hline $\mathrm{c}$ & tx & $/ \mathfrak{g} /$ \\
\hline b & $\mathrm{b}$ & $/ \mathrm{b} /$ \\
\hline $\mathrm{d}$ & $d$ & $/ \mathrm{d} /$ \\
\hline e & $\mathrm{e}$ & /e/ \\
\hline $\mathrm{h}$ & $\mathrm{h}$ & $/ \mathrm{h} /$ \\
\hline $\mathrm{j}$ & $\mathrm{j}$ & $/ d z /$ \\
\hline $\mathrm{k}$ & $\mathrm{k}$ & $/ \mathrm{k} /$ \\
\hline $\mathrm{m}$ & $\mathrm{m}$ & $/ \mathrm{m} /$ \\
\hline $\mathrm{n}$ & $\mathrm{n}$ & $/ \mathrm{n} /$ \\
\hline $\mathrm{p}$ & $\mathrm{p}$ & $/ \mathrm{p} /$ \\
\hline $\mathrm{r}$ & $\mathrm{r}$ & $/ \mathrm{r} /$ \\
\hline $\mathrm{S}$ & $\mathrm{s}$ & $/ \mathrm{s} /$ \\
\hline $\mathrm{t}$ & $\mathrm{t}$ & $/ \mathrm{t} /$ \\
\hline w & w & $/ \mathrm{w} /$ \\
\hline $\mathrm{x}$ & $\mathrm{x}$ & $\mid \mathrm{x} /$ \\
\hline , & , & $/ \mathrm{R} /$ \\
\hline
\end{tabular}

Fonte: Elaborado pela autora.

Não houve qualquer alteração acerca de tom e laringalização, que permaneceram sem qualquer sinalização na escrita, e a nasalidade continuou a ser marcada pelo til, com algumas complicações. $\mathrm{O}$ uso do acento circunflexo em $<\hat{a}>$, que corresponde a $/ \partial /$, gerou um conflito na grafia de sua contraparte nasal, / ̃̃/, pois deveria ser grafada $<\tilde{\hat{a}}>$; porém, a vogal nasal passou a $<\tilde{a}>$, de modo que /ã/ e /ã/ têm a mesma representação na escrita, ou seja, $<\tilde{a}>$. Por exemplo, wenã'a 'castanha (ouriço)' e jarãi'a 'laranja (fruta)' têm a mesma $\operatorname{vogal}<\tilde{a}>$ na escrita, mas vogais distintas na fala: /wenə̃-Pa/ e /ḑarãj-?a/; e a grafia da primeira é variável: wenẫi /wenãj/ 'castanha (fruto)'.

As três variantes fonéticas da nasal velar, [n, $\left.{ }^{\mathrm{g}} \mathrm{n}, \mathrm{\eta}\right]$, são grafadas de acordo com o respectivo alofone: [n] é <nh>, akunhe [akonẽ] 'colar'; ["ำ] é <gn>,

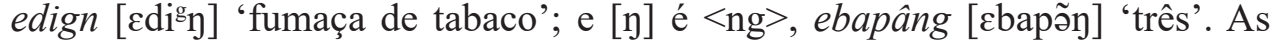


demais nasais, /m, n/, não sofreram alterações, apesar de exibirem a mesma regra alofônica de pré-oralização. O quadro a seguir mostra as mesmas palavras grafadas em uma e na outra proposta. ${ }^{8}$

Quadro 5. Comparação das formas grafadas segundo as propostas de M. Crofts e R. Monserrat

\begin{tabular}{|c|c|c|}
\hline $\begin{array}{c}\text { MONSERRAT } \\
\text { (1996) }\end{array}$ & $\begin{array}{l}\text { CROFTS-SIL } \\
(\text { anos 60) }\end{array}$ & PORTUGUÊS \\
\hline âk'a & uk'a & 'casa' \\
\hline akuba & akoba & 'banana' \\
\hline ârã & ũrũ & 'rede' / 'maracanã (ave)' \\
\hline burũbâ & bõrõbu & 'fio de algodão' \\
\hline beiu'a & beyo'a & 'beiju' \\
\hline daxadign & daxadig & 'fumaça' \\
\hline daje & daje & 'queixada' \\
\hline datxe & dace & 'gavião' \\
\hline hai & (h)ay & 'paca'/'bicho-preguiça' \\
\hline itxo & ico & 'cesto de alguém' \\
\hline ka’ãma & ka'ũma & 'não, nada' \\
\hline ka'ung & ka'õ $\tilde{g}$ & 'varrer' \\
\hline mãng & mũ $\tilde{g}$ & 'encostar' \\
\hline wâi & wũy & 'longe' / 'porto' \\
\hline
\end{tabular}

Fonte: Elaborado pela autora com base em Crofts (1985) e Monserrat (1996)

Segundo Monserrat (1996: 2), “A nova ortografia foi testada e discutida com alguns informantes índios alfabetizados em português e com as irmãs da Missão [Cururu], tendo-se revelado satisfatória."

\section{A pronúncia das letras}

A circulação de diferentes alfabetos levou a inconsistências na escrita, podendo-se encontrar, com frequência, várias versões escritas de uma mesma palavra, como mostram os exemplos a seguir (Picanço 2012a: 419-20).

a) bicho-preguiça: a'y, ay, a'i, ai, hay

b) onça: wida, wi'da' wi'da, wid'a

8 Palavras com duas traduções referem-se àquelas cuja distinção é tonal ou de laringalização. Como nenhum dos dois é marcado na escrita, essas palavras são homógrafas. 
c) gavião: dace, datxe, datche, datje

d) queixada: daje, dadze, dadje

e) rato: tag̃e, tanhẽ, tañe

f) pulga: nõg̃'a, nõng'a

g) macaco: tawe, taue

h) tatu: daydo, daido, da'ido

Além do conflito de alfabetos, Picanço também atribui as discrepâncias a uma falha no ensino-aprendizagem da escrita, que não conta com professores treinados, nem com materiais didáticos adequados para o ensino da escrita. Isso pode ser reflexo do papel que a escrita assumiu desde seu início, ora com finalidade religiosa, ora ajustada à língua majoritária. Como destaca Picanço (2012b:39), “As consequências imediatas são o desprestígio da língua escrita e a desmotivação de seu uso na comunidade, fazendo com que o ensino da língua materna perca a sua importância na preservação e na divulgação da língua."

As regras que regem cada proposta ortográfica nunca foram devidamente esclarecidas em nenhum dos trabalhos, até recentemente, quando Picanço (2012b) publicou uma monografia sobre a fonologia e a ortografia do Mundurukú. O estudo adota a proposta de Marjorie Crofts e colegas, por ser a que melhor representa os sons da língua, a com maior número de materiais impressos e a mais conhecida na comunidade. Além de trabalhar cada letra do alfabeto em relação à fonologia da língua, Picanço sugere seu reordenamento e a adoção de nomes que reflitam os sons representados, em vez dos nomes correspondentes no Português. Desse modo, $<\mathrm{c}>$ seria nomeada txê, e não cê; $<\mathrm{j}>$ seria djê, não jota; $<\mathrm{u}>$ seria â, não $u$; o apóstrofo receberia o nome de glotal, e assim por diante.

\section{Quadro 6. Ordem e nomes das letras do alfabeto Mundurukú, de acordo com} Picanço (2012b)

\begin{tabular}{|c|c|c|c|c|c|c|c|c|c|c|}
\hline $\mathbf{a}$ & $\mathbf{b}$ & $\mathbf{c}$ & $\mathbf{d}$ & $\mathbf{e}$ & $\tilde{\mathbf{g}}$ & $\mathbf{h}$ & $\mathbf{i}$ & $\mathbf{j}$ & $\mathbf{k}$ & $\mathbf{m}$ \\
$a$ & $b \hat{e}$ & $t x \hat{e}$ & $d \hat{e}$ & $\mathrm{e}$ & $n h \hat{e}$ & $h a$ & $i$ & $d j \hat{e}$ & $k a$ & $m \hat{e}$ \\
\hline $\mathbf{n}$ & $\mathbf{o}$ & $\mathbf{p}$ & $\mathbf{r}$ & $\mathbf{s}$ & $\mathbf{t}$ & $\mathbf{u}$ & $\mathbf{w}$ & $\mathbf{x}$ & $\mathbf{y}$ &, \\
$n \hat{e}$ & $\hat{o}$ & $p \hat{e}$ & $r \hat{e}$ & $s \hat{e}$ & $t \hat{e}$ & $\hat{\mathrm{a}}$ & $w \hat{e}$ & $c h \hat{e}$ & $y \hat{e}$ & glotal \\
\hline
\end{tabular}

Fonte: Adaptado de Picanço (2012b: 41-42)

Ainda nesse estudo, Picanço emprega, como exercício, uma adaptação na escrita para sinalizar o tom e a laringalização, utilizando o acento agudo para marcar o tom alto e o grave para marcar a laringalização; uma vogal sem qualquer dos dois acentos corresponde ao tom baixo, não laringalizado, 
conforme ilustrado em um dos textos, extraído de Picanço (2012b: 43): Ikibit wexík'a káy. Wexík'a kàkè ixí duk'á be. Ikibit oájẽm jexí duk'á be. Íté wa'é kug̃. Ikibit wexik'a káy. I'it tak wexik'a káy. I'it wá.

A utilização da marcação suprassegmental como exercício deve-se ao fato de que a monografia originou-se de um material didático elaborado para uma disciplina da grade curricular da Licenciatura Específica para Formação de Professores Indígenas/Turma Mundurukú, oferecida pela Faculdade de Educação, Universidade Federal do Amazonas. Como já apontado anteriormente, Mundurukú não é mais falado pela comunidade do Amazonas há pelo menos três gerações. Para eles, a escrita não é tão transparente quanto para os falantes da língua. Nesse sentido, a marcação de tom e laringalização, assim como a pronúncia das letras, pode melhor auxiliá-los em seus esforços para revitalizar a língua e seu ensino nas escolas locais.

\section{Considerações finais}

Os três momentos da história da escrita Mundurukú revelam bem sua função primária desde que foi instituída, seja como um instrumento facilitador da prática religiosa ou do ensino da Língua Portuguesa. Já se passaram quase 100 anos desde a primeira obra escrita em Mundurukú, um livro de catecismo de autoria de Frei Hugo Mense, missionário franciscano. No entanto, a escrita parecia estar voltada para os próprios missionários, seu aprendizado da língua e a tradução de ensinamentos religiosos, tanto que não há relatos do ensino da língua materna, somente do português, na escola fundada por eles.

O segundo momento foi marcado pela proposta de uma ortografia fundamentada em análises linguísticas mais cuidadosas da língua, conduzidas principalmente por Marjorie Crofts, linguista missionária do SIL, na década de 1960. Pode-se considerá-la como a ortografia que melhor identifica a língua Mundurukú, graças aos materiais impressos produzidos, como cartilhas para o ensino do alfabeto, dicionário, livros de leitura e de lendas. Por outro lado, a escrita tinha ainda como prioridade a tradução de textos religiosos, mostrando que, novamente, sua função era promover a evangelização da comunidade, com o ensino assumindo uma função secundária. Mesmo com tão pouco tempo de existência, o alfabeto sofreu alterações parciais, tornando-o mais semelhante ao português, em um trabalho conduzido pela professora Ruth Monserrat, na década de 1990.

Entender um pouco desse percurso histórico contribui para uma abordagem mais adequada das discrepâncias observadas no uso da escrita. Tanto no contexto de falantes quanto de não falantes da língua, conhecer como e quais traços da fala são representados graficamente é fundamental para fortalecer o prestígio local da língua, dando à ortografia Mundurukú uma identidade própria. Só 
assim a escrita começa a adquirir autonomia e ser mais valorizada como marca identitária e com funções sociais e culturais atribuídas por e para a comunidade.

\section{Referências}

Barros, Maria Cândida Drumond Mendes. 2004. A missão Summer Institute of Linguistics e o indigenismo latino-americano: história de uma aliança (décadas de 1930 a 1970). Revista de Antropologia 47(1), 45-85.

Braun, Ilse \& Marjorie Crofts. 1965. Mundurukú phonology. Anthropological Linguistics 7(7), 23-39.

Cabá, Amâncio \& Catarina Sau. 1970. Aypapayũ'ũm 'ũm ekawẽn: histórias dos antigos Mundurukú - Português. Brasília: Summer Institute of Linguistics.

Collevatti, Jayne Hunger. 2009. A invenção (franciscana) da cultura Munduruku: sobre a produção escrita dos missionários da Província de Santo Antônio. Revista de Antropologia 52(2), 633-676.

Crofts, Marjorie. 1985. Aspectos da Língua Mundurukú. Brasília: Summer Institute of Linguistics.

Crofts, Marjorie. 1967. Notas sôbre dois dialetos do Mundurukú. Atas do Simpósio sobre a Biota Amazônica 2 (Antropologia), 85-91.

Crofts, Marjorie. 1973. Gramática Mundurukú. Brasília: Summer Institute of Linguistics.

Crofts, Marjorie. 1976. Must tone always be written in a tonal language? The Bible Translator 27, 127-34.

Góes Neto, Antônio Fernandes. 2015. O Novo Testamento em nyengatu (1973): um capítulo na história das traduções bíblicas para línguas indígenas. Mestrado em Estudos da Tradução, Universidade de São Paulo.

Katz, L. \& R. Frost. 1992. The reading process is different for different orthographies: the orthographic depth hypothesis. In R. Frost \& L. Katz (Eds.), Orthography, Phonology, Morphology, and Meaning (pp. 67-84). Amsterdam: Elsevier North Holland Press.

Kempf, Valter. 1944. A contribuição franciscana para o conhecimento da tribo dos Mundurucus. Vozes de Petrópolis 2, Rio de Janeiro.

Mense, Frei Hugo (O. F. M.) 1924. Cabi-ä. Pequeno catecismo no idioma mundurucú. In-8.0 Hugo Mense OFM, Bahia (S. Francisco).

Mense, Frei Hugo (O. F. M.) 1947. Língua mundurucú: vocabulários especiais: vocabulários apalaí, uiabói e maué. Comentários de R. F. Mansur Guérios, Válter Kempf e Aryon Dall'Igna Rodrigues. Arquivos do Museu Paranaense VI, 107-148, Curitiba: Museu Paranaense.

Monserrat, Ruth Maria Fonini. 1996. Vocabulário Mundurukú-Português. SEC/PARÁ (Manuscrito).

Monserrat, Ruth Maria Fonini. 2000. Dicionário Myky-Português e vocabulário 
Munduruku-Português, v. 1, Caxias do Sul: EDUCS.

Picanço, Gessiane. 2005. Mundurukú: Phonetics, Phonology, Synchrony, Diachrony. $\mathrm{PhD}$ Thesis, University of British Columbia.

Picanço, Gessiane. 2012a. Language planning for "Mundurukú do Amazonas". Revista Brasileira de Linguística Aplicada 12(2), 405-423.

Picanço, Gessiane. 2012b. Introdução ao Mundurukú: fonética, fonologia e ortografia. Cadernos de Etnolingüistica, Série Monografias, 3.

Richter, Thomas \& Michael Drummen. 2020. In 80 Büchern um die Welt: Katalog zur Ausstellung kirchenhistorischer Bestände in der Missionsbibliothek und katholischen Dokumentationsstelle mikado in Aachen (pp. 244-247).

SIL-Summer Institute of Linguistics. 1967. O Evangelho segundo São Marcos na lingua mundurukú. Edição experimental, Rio de Janeiro. 